\title{
Prostaglandins antagonistically control Bax activation during apoptosis
}

\author{
L Lalier $^{1,2,3}$, P-F Cartron ${ }^{1,2}$, C Olivier ${ }^{1,2,4}$, C Logé $e^{5}$, G Bougras ${ }^{1,2}$, J-M Robert ${ }^{5}$, L Oliver ${ }^{1,2}$ and FM Vallette ${ }^{\star, 1,2}$
}

The Bax protein (Bcl-2-associated X protein) is pivotal for the apoptotic process. Bax, which resides in an inactive form in the cytosol of healthy cells, is activated during the early stages of apoptosis and becomes associated with mitochondria through poorly understood mechanisms. In this study, we show that a family of bioactive lipids, namely prostaglandins, regulates Bax-dependent apoptosis. The prostaglandin $\mathrm{E}_{2}\left(\mathrm{PGE}_{2}\right)$ or its derivative $\mathrm{PGA}_{2}$ binds to $\mathrm{Bax}$, induces its change of conformation, and thereby triggers apoptosis. A cysteine present in the loop between the two transmembrane $\alpha$-helices of Bax, Cys 126 is critical for its activation. $\mathrm{PGD}_{2}$ inhibits $\mathrm{PGE}_{2}$ binding to $B a x$ and $\mathrm{PGE}_{2}$-induced apoptosis, as well as cell death induced by staurosporine and UV-B in various cell lines. This result is consistent with the fact that apoptosis is accompanied during these treatments by an increase in $\mathrm{PGE}_{2}$. This process is distinct, yet cooperative, from that involving the BH3-only protein Bid. Our results establish that the $\mathrm{PGE}_{2} / \mathrm{PGD}_{2}$ balance is involved in a new early mechanism of control in the activation of Bax during apoptosis.

Cell Death and Differentiation (2011) 18, 528-537; doi:10.1038/cdd.2010.128; published online 22 October 2010

Members of the $\mathrm{Bcl}-2$ (Bcl-2-associated $\mathrm{X}$ protein) family of proteins determine both the initiation and the execution of mitochondrial outer membrane permeabilization (MOMP) and the subsequent apoptosis. These proteins share a similar solution structure, and are subdivided into two groups: antiapoptotic proteins (e.g., Bcl-2, Bcl-XI, Bcl-W and Mcl-1) and proapoptotic proteins, which control apoptosis through complex interaction with each other. Proapoptotic proteins are further subdivided into multidomain proteins (namely, Bax, Bak and Bok) and BH3-only proteins (e.g., Bim, Bad, Bid, Puma or Noxa) whose homology with Bcl-2 is limited to the $\mathrm{BH} 3$ domain. $\mathrm{BH} 3-o n l y$ proteins function as upstream sensors that selectively respond to specific signals and promote the proapoptotic function of Bax and/or Bak. Both in vivo and in vitro experiments have proved that the conformation of monomeric Bax/Bak change upon induction of apoptosis, leading to their oligomerization in the mitochondrial membrane and MOMP. ${ }^{1-3}$

How Bax and Bak are activated is a matter of debate. ${ }^{2,4}$ A widely accepted model proposes that some BH3-only proteins called 'activators' (tBid, Bim and Puma) induce the Bax/Bak apoptotic conformational change through transient physical interaction in a 'hit and run' manner. Another group named 'enabler' (also called derepressor or sensitizer) can release Bax and Bak from antiapoptotic proteins, which in turn trigger MOMP. ${ }^{1-3}$ The existence of a direct interaction of Bax/Bak with $\mathrm{BH} 3-$ only proteins has been challenged, suggesting the existence of alternative mechanisms responsible for the activation of Bax or Bak. A change in $\mathrm{pH}$ or temperature has also been shown to facilitate the transition between the inactive and active states of Bax, supporting a role for nonprotein interactions in apoptosis. ${ }^{5-7}$ However, the physiological occurrence for this type of regulation has not been provided in these studies.

We have recently shown that microsomal prostaglandin $E_{2}$ synthase 1 (mPGES-1), the enzyme responsible for the synthesis of $\mathrm{PGE}_{2}$ downstream of cyclooxygenase 2 (COX-2), facilitates a Bax-dependent apoptosis in human gliomas. ${ }^{8}$ The exact role of prostaglandins during apoptosis remains unclear, especially in the case of $P G E_{2}$, which has been described, to affect differently programmed cell death depending upon the cellular types and/or contexts (see e.g., Huang et al..${ }^{9}$ Sheng et al. ${ }^{10}$ and Tessner et al. ${ }^{11}$ ). However, most studies have essentially been focused on extracellular $\mathrm{PGE}_{2}$ and its binding to EP receptors. In this study, we describe the role of intracellular $\mathrm{PGE}_{2}$ and its closely related prostaglandin $\mathrm{PGD}_{2}$ on Bax activation.

\section{Results}

$\mathrm{PGE}_{2}$-derived prostaglandins specifically induce $\mathrm{Bax}$ activation. We have recently shown that $\mathrm{PGE}_{2}$ microinjection induced a Bax-dependent cell death in human glioma primary cultures. ${ }^{8}$ The microinjection of $\mathrm{PGE}_{2}$ into the cytoplasm of a rat fibroblast cell line (i.e., Rat-1) induced a substantial and rapid cell death (i.e., $>40 \%$ cell death

\footnotetext{
${ }^{1}$ INSERM U 892, Equipe Labellisée Ligue contre le Cancer, 8 Quai Moncousu, Nantes Cedex 01, France; ${ }^{2}$ Faculté de Médecine, Université de Nantes, Nantes Atlantique Université, Nantes Cedex 01, France; ${ }^{3}$ Département de Biologie Oncologique, Centre de Lutte Contre le Cancer René Gauducheau, Nantes, Saint Herblain Cedex, France; ${ }^{4}$ Laboratoire de Toxicologie, Faculté de Pharmacie, Nantes Cedex 01, France and ${ }^{5}$ Département de Pharmacochimie, Cibles et Médicaments des Infections, de l'Immunité et du Cancer, IICIMED-EA 1155, UFR Sciences Pharmaceutiques, Université de Nantes, Nantes Atlantique Université, Nantes Cedex 01, France ${ }^{*}$ Corresponding author: FM Vallette, IRTUN, UMR892 INSERM Université de Nantes, 8 Quai Moncousu, 44007 Nantes Cedex 01, France.

Tel: + 33 228080324; Fax: + 3322808 0329; E-mail: francois.vallette@ univ-nantes.fr

Keywords: apoptosis; Bax; prostaglandins; cancer

Abbreviations: Bax, Bcl-2-associated X protein; COX-2, cyclooxygenase 2; L-PGDS, lipocalin-like prostaglandin $\mathrm{D}_{2}$ synthase; $\mathrm{mPGES}$-1, microsomal prostaglandin $\mathrm{E}_{2}$ synthase $1 ; \mathrm{PGE}_{2}$, prostaglandin $\mathrm{E}_{2} ; 15$-keto $P \mathrm{PE}_{2}, 15$-keto prostaglandin $\mathrm{E}_{2}$

Received 23.4.10; revised 10.8.10; accepted 10.8.10; Edited by B Zhivotovsky; published online 22.10.10
} 
a

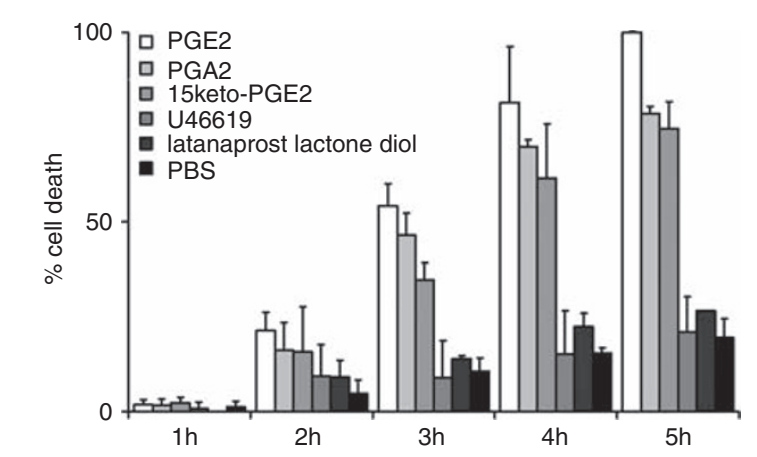

C $\mathrm{PGE}_{2}$
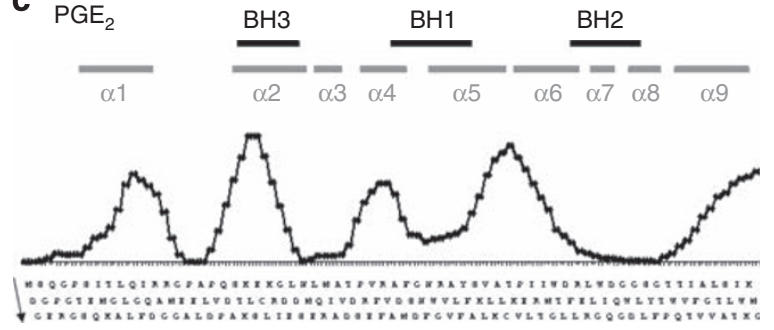

b

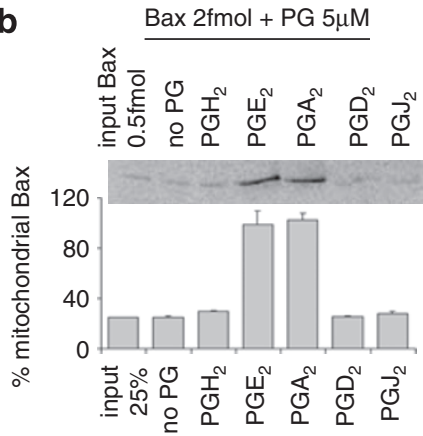

d

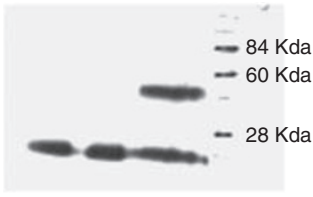

con PGE2 TX100 MW

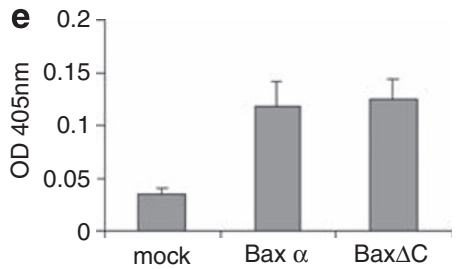

Figure $1 \mathrm{PGE}_{2}$-like prostaglandins specifically activate Bax. (a) Prostaglandins or analogs were microinjected into GBM cells $(20 \mu \mathrm{M}$ injected, corresponding to a $2 \mu \mathrm{M}$ intracellular raise) and cell death in the injected cells was assessed every hour. (b) ${ }^{35} \mathrm{~S}$ in vitro translated Bax was incubated with indicated prostaglandins and then added to isolated mitochondria. Bax translocation was assessed by the amount of mitochondria-associated Bax. (c) A pepscan experiment was carried out with biotinylated PGE ${ }_{2}$ as described in Materials and methods. The gray bars over the graph show the $\alpha$-helices position of Bax and the black bars show the BH domains. (d) Cytosolic Bax was incubated with the cross-linker alone (con), or EGS plus $\mathrm{PGE}_{2}(5 \mu \mathrm{M})$ or $1 \% \mathrm{TX}_{100} \mathrm{PGE}_{2}$ does not induce Bax dimerization. The blot shown is representative from three independent experiments. (e) DU-145 Bax-deficient cells were transfected either with Bax- $\alpha$ or with the H $\alpha 9$-deleted form of Bax (Bax $\Delta \mathrm{C}$ ). Cell lysates were applied to a 96-well plate coated with an anti-Bax antibody (2D2). $\mathrm{PGE}_{2}$ was added to the wells with $\mathrm{PGE}_{2}-\mathrm{AChE}$ as a tracer

within $6 \mathrm{~h}$; Supplementary Figure S1). This result implies that the cell death inducing activity of $\mathrm{PGE}_{2}$ is not restricted to malignant cells, to the nervous system or to human cell lines and thus could be a general feature during apoptosis. To address this question, we have analyzed the impact of cytoplasmic microinjections of $\mathrm{PGE}_{2}$-related prostaglandins on the induction of apoptosis (Supplementary Figure S2). In vivo, $\mathrm{PGE}_{2}$ is rapidly transformed by a non-enzymatic dehydration into $\mathrm{PGA}_{2}$ or is metabolized into an inactive form (i.e., 15-keto $\mathrm{PGE}_{2}$ ) by 15-hydroxy-prostaglandin dehydrogenase. ${ }^{12}$ As shown in Figure 1a, the microinjection into an established glioma cell line (U251) of $\mathrm{PGA}_{2}$ and 15-keto $P G E_{2}$ induced cell death, as efficiently as $\mathrm{PGE}_{2}$, whereas the microinjection of $\mathrm{U} 46619$ (the non-metabolic version of $\mathrm{PGH}_{2}$, the precursor of $\mathrm{PGE}_{2}$ ), or that of the closely related molecule latanoprost lactone diol did not affect cell viability. These results suggest that a 'non-active' physiological form of $\mathrm{PGE}_{2}$ (i.e., 15-keto $P \mathrm{PE}_{2}$ ) is still capable of activating apoptosis but not its precursor (i.e., $\mathrm{PGH}_{2}$ ). Of note, $\mathrm{PGD}_{2}$, the other major metabolite of $\mathrm{PGH}_{2}$ in the central nervous system, did not induce cell death in glioma cells, as previously described. ${ }^{8}$ Consistent with the microinjection experiments, neither $\mathrm{PGH}_{2}$ nor $P G D_{2}$ and its metabolite $P G J_{2}$ resulted in the mitochondrial relocalization of $\mathrm{Bax}$ in a cell free assay, whereas $\mathrm{PGE}_{2}$ and $\mathrm{PGA}_{2}$ (Figure 1b) and 15-keto $\mathrm{PGE}_{2}$ (data not shown) triggered Bax translocation to the organelle. $\mathrm{PGE}_{2}$ did not trigger the release of cytochrome $c$ from mitochondria unless Bax is present (Supplementary Figure S3).

To determine the binding sites of $\mathrm{PGE}_{2}$ on Bax, we used a linear peptide scan we previously described. ${ }^{13}$ In this assay, the whole sequence of Bax was decomposed into 12-mer peptides (overlapping by 10 residues) covalently bound to a nitrocellulose membrane, which was incubated with biotinylated $\mathrm{PGE}_{2}$. Figure $1 \mathrm{c}$ shows that biotinylated $\mathrm{PGE}_{2}$ was able to interact with several $\alpha$-helices $(\mathrm{H} \alpha)$ in Bax but showed a maximal binding to the $\mathrm{H} \alpha 2$ (BH3 domain), the loop formed between the $\mathrm{H} \alpha 5$ and $\mathrm{H} \alpha 6$ and last $\mathrm{H} \alpha$ present in its $\mathrm{C}$-terminal end, $\mathrm{H} \alpha 9$. These domains have been shown to have an important role in the interaction of Bax with mitochondrial membranes and/or Bax oligomerization and interaction with $\mathrm{Bcl}-\mathrm{XI}{ }^{14-17}$ Bax-induced release of mitochondrial cytochrome $c$ is often related to its oligomerization through the $\mathrm{BH} 3$ domain and the exposure of the $\mathrm{H} \alpha$ present in its C-terminal end. ${ }^{3}$ However, as $\mathrm{PGE}_{2}$ did not trigger Bax oligomerization (Figure 1d) and the deletion of the $\mathrm{H} \alpha 9$ of Bax did not impair its ability to interact with $\mathrm{PGE}_{2}$ (Figure 1e), we conclude that these domains are not fundamental for $\mathrm{PGE}_{2}$-induced activation of Bax. 
$\mathrm{PGE}_{2}$ binds the $\mathrm{H} \alpha 5-\alpha 6$ hairpin of $\mathrm{Bax}$ and the resulting activation of Bax requires the cysteine 126 residue. Given the widely reported affinity of cyclopentenone prostaglandins for cysteine residues, ${ }^{18,19}$ we questioned the ability of cysteine reagents, such as the competitive inhibitor $\mathrm{N}$-acetylcysteine (NAC) or the cysteine blocker iodoacetamide, to interfere with the $P G E_{2}-B a x$ interaction. As shown in Figure $2 \mathrm{a}$, both reagents inhibit the interaction suggesting that the free access to the regions including one or both cysteine residues of Bax was crucial for the physical interaction with $\mathrm{PGE}_{2}$. Consistent with this observation, the addition of NAC to the culture medium of the glioma cell line (LN18) before $\mathrm{PGE}_{2}$ microinjection protected against cell death (Figure $2 \mathrm{~b}$ ). We thus performed site-directed mutagenesis experiments to assign the role of both cysteine residues in Bax-to-PGE $\mathrm{PG}_{2}$ binding. Bax-deficient DU-145 cell are not sensitive to microinjected $\mathrm{PGE}_{2}$-induced cell death (Figure 2c). The transfection of wild-type or C62S-mutated Bax rendered these cells sensitive to microinjected $\mathrm{PGE}_{2}$ induced cell death, whereas that of C126S-mutated and the double-mutated Bax (C126S and CCSS, respectively) inhibited the sensitivity toward $\mathrm{PGE}_{2}$ (Figure $2 \mathrm{c}$ ). Of note, cells transfected with any of the mutants were still responsive to apoptotic inducers staurosporine and UV-B, although the C126S mutation provoked a non-significant decrease in the maximal cell death (Supplementary Figure S4). As cysteine mutants of Bax were still able to interact with $\mathrm{PGE}_{2}$ (Supplementary Figure S5), we conclude that other residues close to C126 also may be involved in the interaction and thus that this cysteine residue is essentially involved in the subsequent activation of $\mathrm{Bax}$ induced by $\mathrm{PGE}_{2}$ rather than its binding. This was further substantiated by the fact that the ability of $\mathrm{PGE}_{2}$ to induce a change in the conformation of Bax was suppressed in the C126S mutant (Figure 3b, lane 0).

Mass spectrometry showed no covalent binding between Bax and $\mathrm{PGE}_{2}$, or its derivative $\mathrm{PGA}_{2}$ (data not shown). We performed a molecular modeling study of a non-covalent binding between the known structure of $B a x$ and $P G E_{2}$ (Figure 2d). To explore the $\mathrm{PGE}_{2}$ binding mode in Bax, we first examined the solvent accessible surface area of the protein structure. A narrow hydrophobic pocket is present in Bax in close proximity to $\mathrm{C} 126$. This region consists of the $\mathrm{C}$-terminal part of $\mathrm{H} \alpha 5$, the $\mathrm{N}$-terminal region of $\mathrm{H} \alpha 6$ and the loop between $\mathrm{H} \alpha 3$ and $\mathrm{H} \alpha 4$ (Figure $2 \mathrm{~d}$ ). $\mathrm{PGE}_{2}$ was then subjected to docking using an $\mathrm{H}$-bond constraint approach with the probable target C126 thiol group. The most stable docking model is shown in

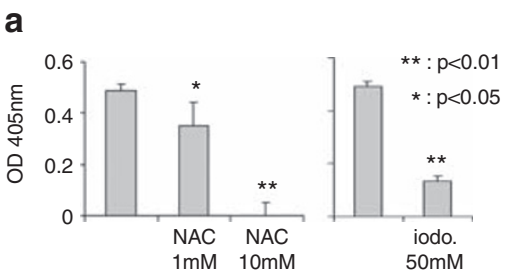

C

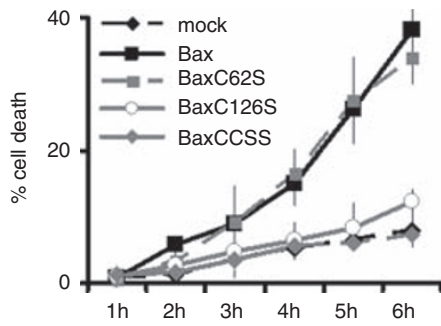

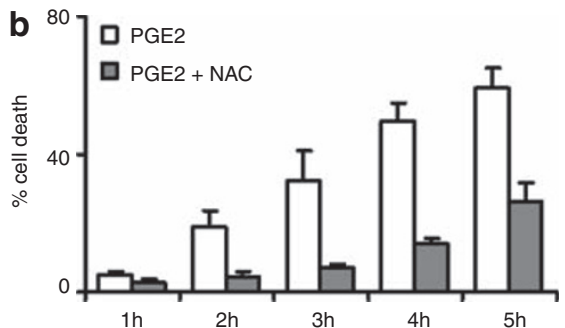
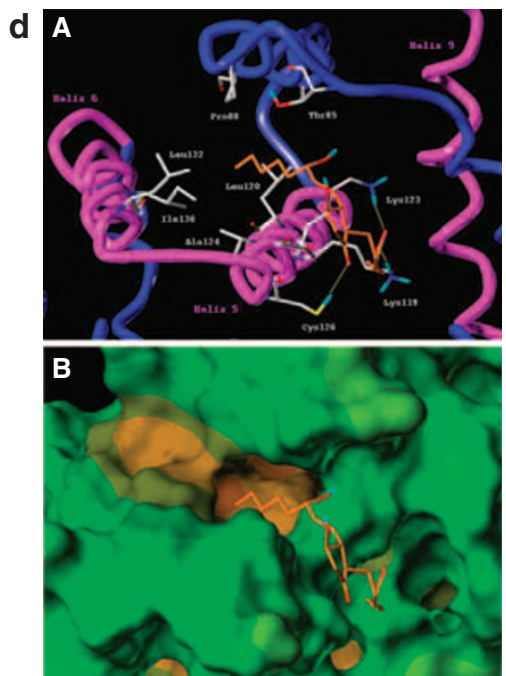

Figure 2 Bax $\mathrm{C} 126$ residue is necessary to $\mathrm{PGE}_{2}$-induced activation. (a) The same assay as in Figure $1 \mathrm{~d}$ was carried out with Bax-expressing cell lysates. The assay was performed after lysates incubation with $\mathrm{N}$-acetylcysteine (NAC) or iodoacetamide (thiol reagent) when indicated. (b) $\mathrm{PGE}_{2}(20 \mu \mathrm{M}$, corresponding to a $2 \mu \mathrm{M}$ intracellular raise) was microinjected into glioma cells, with or without previous treatment by $10 \mathrm{mM}$ NAC. Cell death was assessed as in Figure 1a. (c) Bax mutants were transfected into a Bax-deficient cell line (DU-145). PGE $_{2}$ microinjection was then performed and cell death was assessed every hour. (d) The interaction between $P E_{2}$ and Bax was illustrated in the neighborhood of $\mathrm{C} 126$. The most stable docking model is shown (A). The ionic or hydrogen bonds are indicated as yellow dotted lines. MOLCAD solvent accessible surface area (program Sybyl 7.2) of the NMR structure of protein Bax, with the lipophilic potential mapped onto the surface (B). The color codes indicate blue areas for hydrophilic, brown for lipophilic and green for neutral 


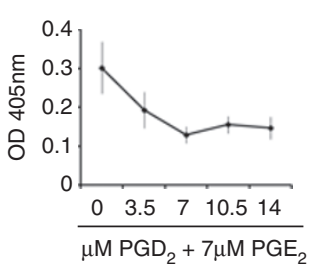

b

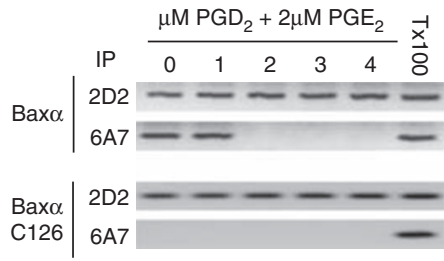

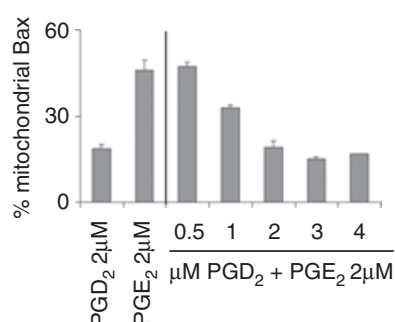

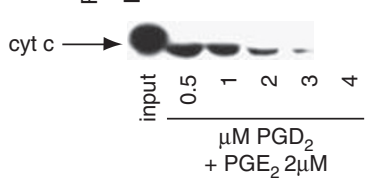

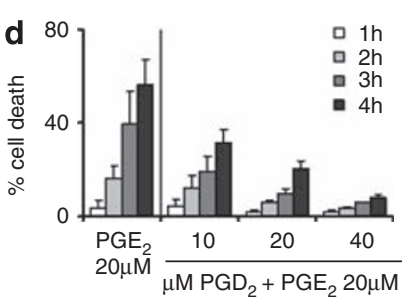

a $1 \mathrm{~h}$

$4 \mathrm{~h}$

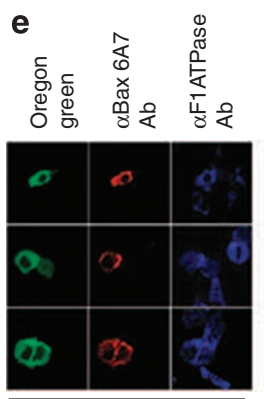

$\mathrm{PGE}_{2} 20 \mu \mathrm{M}$

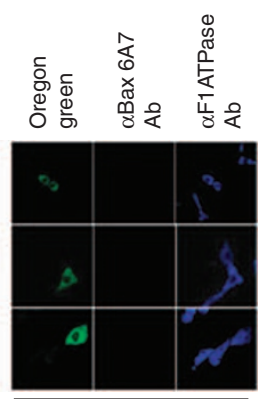

$\mathrm{PGE}_{2} 20 \mu \mathrm{M}$ $+\mathrm{PGD}_{2} 20 \mu \mathrm{M}$

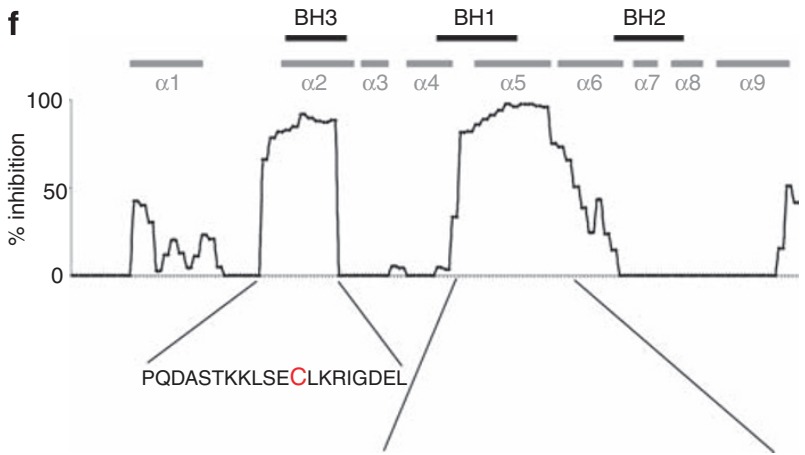

GNFNWGRVVALFYFASKLVLKALCTKVPEL

Figure $3 \mathrm{PGD}_{2}$ inhibits $\mathrm{PGE}_{2}-\mathrm{Bax}$ interaction and subsequent Bax activation. (a) The same enzyme immunoassay as described in Figure 1d between fixed Bax and AchE-PGE 2 was realized in the presence of raising amount of $\mathrm{PGD}_{2}$. (b) ${ }^{35}$ S-IVT-Bax or Bax ${ }^{\mathrm{C} 126 \mathrm{~S}}$ was incubated with indicated prostaglandins and immunoprecipitated with the $6 A 7$ antibody, which solely recognizes the activated conformation of Bax. IVT Bax was detected by autoradiography after SDS-PAGE. Equimolar amount of PGD 2 inhibits the activation of Bax induced by $\mathrm{PGE}_{2}$. The $2 \mathrm{D} 2$ antibody was used as a positive control for Bax immunoprecipitation and Triton X100 (TX100) was used as a positive control for Bax activation. (c) ${ }^{35} \mathrm{~S}$ IVT-Bax was incubated with indicated prostaglandins and added to isolated mitochondria as described in Figure $1 \mathrm{~b}$. The subsequent mitochondrial release of Cytochrome $c$ was assessed by western blot for each condition. Input is the total amount of mitochondrial Cytochrome $c$. (d) Glioma cell death was monitored following $\mathrm{PGE}_{2}$ microinjection. In microinjection experiments, injected solutions are diluted about $1 / 10$ in the cell. The experiment can thus be considered as representative for a $2 \mu \mathrm{M}$ raise in $\mathrm{PGE}_{2}$ intracellular concentration. The indicated amount of $\mathrm{PGD}_{2}$ was co-injected with $\mathrm{PGE}_{2}$. (e) Microinjected cells were fixed and stained with the 6 A7 antibody raised against the active conformation of Bax. The anti- $F_{1}-A T P a s e$ antibody was used as a positive control. Cells were observed by confocal microscopy. (f) A pepscan experiment was realized as described in Figure 1e with biotinylated $P G E_{2}$ and non-labelled $P \mathrm{PD}_{2}$. ECL revealed bound $P G E_{2}$ and the percentage of inhibition versus $\mathrm{PGE}_{2}$ alone was determined

Figure 2D. The carboxylate group of the $\alpha$-chain in $P G_{2}$ is involved in salt bridges with the terminal amino groups of K119 and $\mathrm{K} 123$ in $\mathrm{Bax} \mathrm{H} \alpha 5$. Moreover, the $\omega$-chain in $\mathrm{PGE}_{2}$ was incorporated into the hydrophobic pocket, composed mainly of residues P88, L120, A124, L132 and I136 in Bax and could stabilize the molecule through hydrophobic interactions. Interestingly, this putative interaction domain of Bax with $\mathrm{PGE}_{2}$ appears to be different from that ascribed to the $\mathrm{BH} 3-o n l y$ proapoptotic protein Bim. ${ }^{20}$ Of note, the most stable docking models obtained with $\mathrm{PGE}_{2}, \mathrm{PGA}_{2}$ and 15-keto $\mathrm{PGE}_{2}$ are very similar, which is consistent with their common activating ability (Supplementary Figure S6) and with the identical position of the keto group on the cycle (Supplementary Figure S2).

$P G D_{2}$ inhibits the interaction between $P G E_{2}$ and Bax, and the subsequent induction of cell death. Prostaglandins from the $E$ and $D$ series have been widely reported to have opposite roles in their various fields of activities. ${ }^{21-23}$ We thus challenged the impact of $P G D_{2}$ on the $\mathrm{PGE}_{2}$-induced Bax activation. $\mathrm{PGD}_{2}$ inhibited the interaction between $\mathrm{PGE}_{2}$ and $\mathrm{Bax}$ (Figure $3 \mathrm{a}$ ) and counteracted $\mathrm{PGE}_{2}$ ability to activate Bax (Figure $3 \mathrm{~b}$ ) in cell-free assays. The co-incubation of $\mathrm{Bax}$ and $\mathrm{PGE}_{2}$ resulted in $\mathrm{Bax}$ activation and its subsequent translocation to the MOM in isolated mitochondria (Figure 1b). The addition of increasing concentrations of $\mathrm{PGD}_{2}$ precluded this relocalization as well as the consecutive MOMP (Figure 3c). Similarly, the co-injection of $\mathrm{PGD}_{2}$ and $\mathrm{PGE}_{2}$ into glioma cells alleviated the death-inducing ability of $\mathrm{PGE}_{2}$ (Figure $3 \mathrm{~d}$ ). This was substantiated with the observation that the activation of Bax by microinjected $\mathrm{PGE}_{2}$ into $\mathrm{GBM}$ cells, viewed by the labeling with the $6 \mathrm{~A} 7$ antibody and relocalization to mitochondria (Figure $3 e$ left), was totally abolished by equimolar concentrations of microinjected $\mathrm{PGD}_{2}$ (Figure 3e, right). We designed a competitive assay, in which biotinylated-PGE $\mathrm{F}_{2}$ was incubated with a Bax pepscan membrane in the presence of equimolar concentration of unlabeled $\mathrm{PGD}_{2}$ (Figure 3f). The peptide scan experiment revealed that the maximal inhibition of $\mathrm{PGE}_{2}$ binding to Bax elicited by $P \mathrm{PD}_{2}$ was localized to two regions in Bax, namely $\mathrm{H} \alpha 2$ and $\mathrm{H} \alpha 5$ (including the proximal $\mathrm{H} \alpha 6$ ), which contain the two cysteine 
residues of Bax, C62 and C126 (Figure 3f). This is in agreement with the molecular modeling of the interaction between $\mathrm{PGE}_{2}$ and Bax we hypothesized earlier.

$\mathrm{PGE}_{2}$ is associated with cell death and $\mathrm{PGD}_{2}$ with cell survival. We have previously shown that overexpression of mPGES-1, the enzyme responsible for $\mathrm{PGE}_{2}$ synthesis downstream of COX-2, sensitized GBM cells to cell death and that its inhibition decreased the apoptotic threshold. ${ }^{8}$ Other groups, nevertheless, have reported an antiapoptotic role for COX-2 assuming that this effect was mediated solely through the production of $\mathrm{PGE}_{2}$. Given our previous results, we hypothesized that the antiapoptotic effect of COX-2 reported in the literature might be linked to $P G D_{2}$ production by the other enzyme downstream of COX-2 in GBM cells, lipocalin-like $\mathrm{PGD}_{2}$ synthase (L-PGDS). To support our contention, we selectively downregulated mPGES-1, COX-2 or L-PGDS expression in GBM cells. Expression knock-down experiments were performed using two different shRNA sequences for each enzyme, which efficiently downregulated the expression of these enzymes (Supplementary Figure S7). As shown in Figure $4 \mathrm{a}$, the downregulation of mPGES-1 inhibited the apoptosis induced by staurosporine in glioma cells, whereas that of COX-2 enhanced it. This result supported an opposite role for these enzymes during apoptosis. The decreased expression of L-PGDS, similar to COX-2, gave an increase in cell death (Figure 4a). We observed that the inhibition of one of the enzymes influenced the expression of the others in a rather complex manner (data not shown). However, we found that, in all cases, apoptosis was correlated to the mPGES-1/ COX-2 ratio as the higher the ratio, higher the cell death a

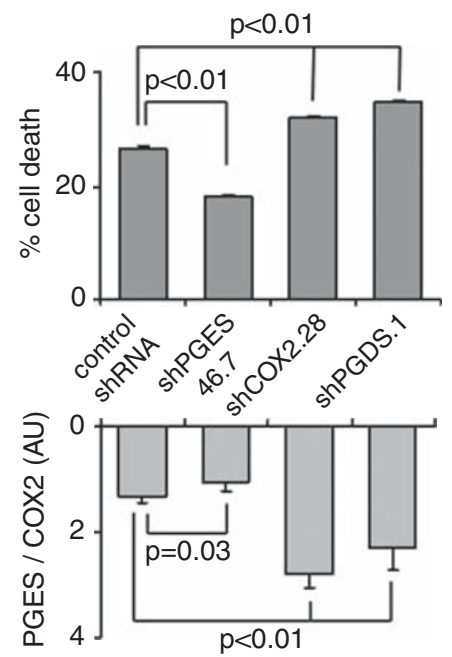

c
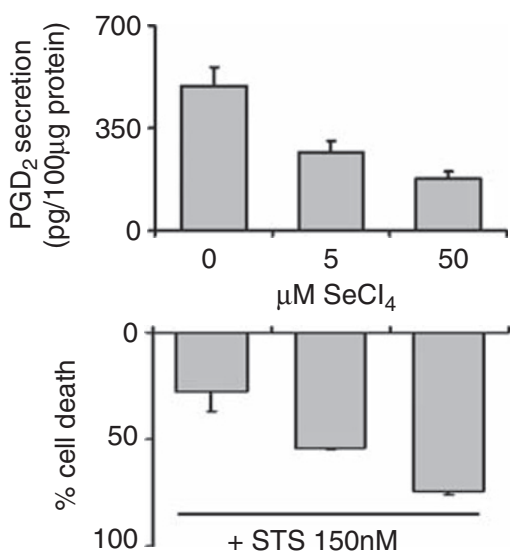

b

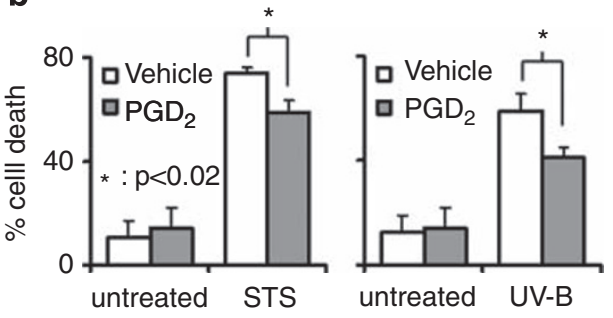

d

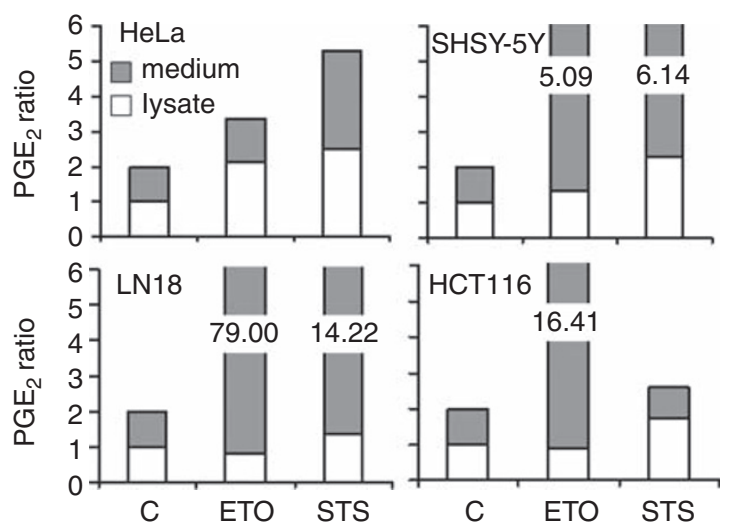

Figure $4 \mathrm{PGE}_{2}$ is related to cell death and $\mathrm{PGD}_{2}$ to cell survival in GBM. (a) GBM cells were transfected with a plasmid encoding for a shRNA sequence targeting the indicated enzyme. Apoptosis was induced by staurosporine ( $150 \mathrm{nM}, 12 \mathrm{~h}$ ), and cell death was measured by Trypan blue exclusion (upper graph). mPGES-1 and COX-2 expression was assessed by western blot and normalized to actin. The ratio is shown on the lower graph. (b) GBM cells were treated by staurosporine (150 nM) or by UV-B irradiation ( $30 \mathrm{~s}$ exposure) $1 \mathrm{~h}$ after $\mathrm{PGD}_{2}$ microinjection $\left(20 \mu \mathrm{M}\right.$, representative for a $2 \mu \mathrm{M}$ raise in $\mathrm{PGD}_{2}$ intracellular concentration). Cell death was assessed among microinjected cells respectively 12 and $18 \mathrm{~h}$ after treatment. (c) Glioma cells were treated simultaneously by 5 or $50 \mu \mathrm{M} \mathrm{SeCl}_{4}$ as indicated on the upper graph. The pH of the $\mathrm{SeCl}_{4}$ solution was checked before treatment. Secreted $\mathrm{PGD}_{2}$ was measured as described in Materials and methods. Cells were then co-treated by Secl 4 and staurosporine. Cell death was measured by Trypan blue exclusion after $16 \mathrm{~h}$ (lower graph). The graph shown is representative for three independent experiments. (d) Four cell lines were

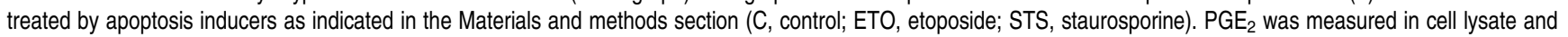
supernatant and normalized by corresponding protein concentration. The graphs represent the increase in $\mathrm{PGE}_{2}$ concentration in treated versus control conditions 
(Figure 4a). The same correlation could be made between the $\mathrm{mPGES}-1 / \mathrm{COX}-2$ ratio and the DEVDase activity in the treated cells, confirming that the cell death observed was apoptosis (Supplementary Figure S8A).

Then, we studied the effect of $P G D_{2}$ on the susceptibility of glioma cells in the induction of apoptosis by various agents. $\mathrm{PGD}_{2}$ microinjection into glioma cells significantly inhibited cell death induced by staurosporine or UV-B irradiation (Figure 4b), whereas the pharmacological inhibition of L-PGDS by $\mathrm{SeCl}_{4}$ sensitized the cells to staurosporineinduced apoptosis (Figure $4 \mathrm{c}$ and Supplementary Figure S8B) as well as UV-induced apoptosis (data not shown). We then asked whether $\mathrm{PGE}_{2}$ was implicated in the cell death induced by cytotoxic agents, namely etoposide or staurosporine in different cell lines. To be able to measure intracellular $\mathrm{PGE}_{2}$ in treated cells, we defined experimental conditions under which apoptosis was induced by etoposide or staurosporine in four different cell lines, representing models of cancer cells from various tissues (i.e., HeLa, SH-SY5Y, LN18, HCT116). As shown in Figure 4d, an increase in $\mathrm{PGE}_{2}$ (intracellular and/or secreted) was observed after $4 \mathrm{~h}$ and before any morphological signs of apoptosis under all conditions and in all cancer cells tested. Of note, the $\mathrm{PGE}_{2}$ concentration observed in the early step of apoptosis was similar to that used to activate Bax in the cell-free assay (data not shown). The increase in $\mathrm{PGE}_{2}$ was also observed in a Bax-deficient GBM cell line (Supplementary Figure S9), a cell line highly resistant to apoptosis, ${ }^{16}$ suggesting that it is not a consequence of cell death. These results show that the increase in $\mathrm{PGE}_{2}$ synthesis is a rapid process that occurs during the early stages of apoptosis.
$\mathrm{PGE}_{2}$ and Bid activate Bax by independent pathways that can cooperate. Among the different $\mathrm{BH} 3-$ only proteins, Bid has been reported to induce the direct activation of Bax. ${ }^{24}$ Bid can activate Bax through either its truncated form tBid or merely its $\mathrm{BH} 3$ domain $\left(\mathrm{BH}_{3}{ }^{\mathrm{Bid}}\right.$ see for example, Moreau et al. ${ }^{25}$ ). We thus questioned whether $\mathrm{PGE}_{2}$ and $\mathrm{BH} 3^{\mathrm{Bid}}$ were redundant in Bax activation. We first observed that the microinjection of sublethal amounts of $\mathrm{PGE}_{2}$ or $\mathrm{BH}^{\mathrm{Bid}}$ induced no cell death within $5 \mathrm{~h}$, whereas the co-injection of sublethal doses of both compounds resulted in a massive cell death within the same time frame (Figure 5a, left), indicating cooperation between $\mathrm{PGE}_{2}$ and $\mathrm{BH}^{\mathrm{Bid}}$ in apoptosis induction. The cell death induced was inhibited by the addition of equimolar (to $P G E_{2}$ ) amount of $\mathrm{PGD}_{2}$ (Figure 5 a left, black squares). Of note, $\mathrm{PGD}_{2}$ was unable to inhibit cell death induced by a lethal concentration of $\mathrm{BH}^{\mathrm{Bid}}$ even at very high concentrations (Figure 5a, right). Similarly, $\mathrm{PGE}_{2}$ induced apoptosis whether Bid expression was repressed or not (Figure $5 b$ ). As shown in Figure $5 c$, in a more physiological situation, the mPGES-1 or L-PGDS overexpression did not significantly affect the sensitivity of glioma cells to TRAIL, an apoptotic inducer targeting the activation of Bax through Bid. ${ }^{16}$ Conversely, the knock down of Bid by shRNA rendered the cells partly resistant to the staurosporine/ $\mathrm{SeCl}_{4}$-induced apoptosis, whereas that of Bax totally abrogated cell death (Figure $5 d$ ). Thus, pharmacological inhibition of $\mathrm{PGD}_{2}$ production reversed the partial resistance to apoptosis in shBid-treated cells, but had no effect on the shBax-treated cells, suggesting a functional cooperation between $\mathrm{PGE}_{2}$ and Bid during staurosporineinduced apoptosis (Figure 5d).
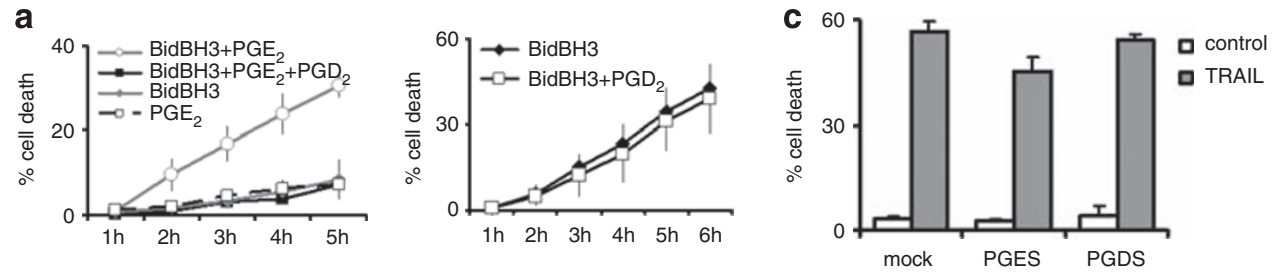

b

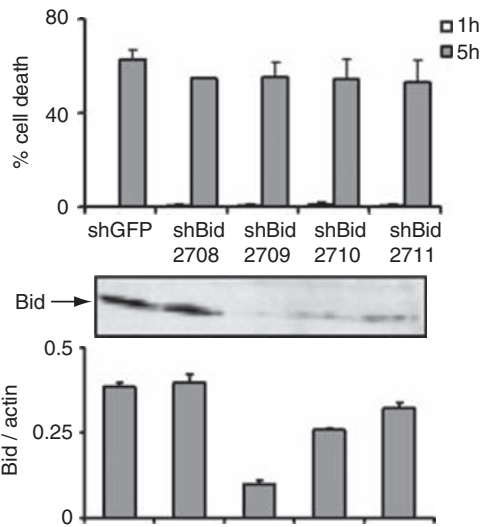

d

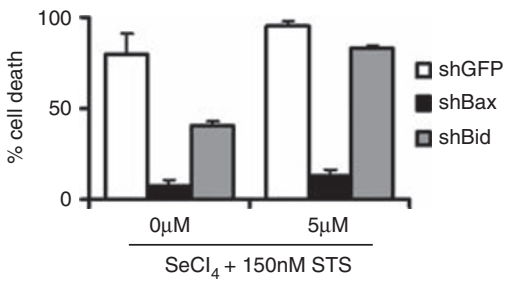

Figure $5 \mathrm{PGE}_{2}$ and Bid are independent activators of Bax. (a) Glioma cells were injected by sub-lethal amounts of $\mathrm{PGE}_{2}$ and BH3 ${ }^{\mathrm{Bid}}$ (respectively, $5 \mu \mathrm{M}$ and $20 \mathrm{nM}$ ) and by an equimolar amount of $\mathrm{PGD}_{2}\left(20 \mu \mathrm{M}\right.$; left graph). Alternatively, $100 \mathrm{nM} \mathrm{BH}{ }^{B i d}$ was injected together with a large excess of $\mathrm{PGD}_{2}(150 \mu \mathrm{M}$; right graph). (b) Bid expression was repressed by four different shRNA lentiviral particles in glioma cells and $\mathrm{PGE}_{2}$ was injected as described earlier. The upper graph shows cell death counting $5 \mathrm{~h}$ after injection and the lower graph indicates the respective shRNA efficiency revealed by western blot analysis of Bid (insert). (c) Glioma cells were transfected by a plasmid encoding for mPGES-1 or L-PGDS cDNA. Cells were treated by TRAIL $(100 \mathrm{nM}, 24 \mathrm{~h})$ and cell death was assessed as described earlier. (d) Bax or Bid expression was repressed in glioma cells by validated shRNA sequences (residual expression $\leq 10 \%$ ) and cells were treated by staurosporine $150 \mathrm{nM} \pm \mathrm{SeCl}_{4} 5 \mu \mathrm{M}$ for $16 \mathrm{~h}$ 
All together these data show that $\mathrm{PGE}_{2}$ and Bid share the same function, namely Bax activation, but do not compete with each other and can instead cooperate in this function. This is corroborated by the fact that the binding sites of Bax implicated in their respective activating functions are distinct.

\section{Discussion}

Prostanoids possess both pro- and antiapoptotic functions that seem to depend on the differentiation stage and tissue origin of the treated cells. ${ }^{26}$ To give a few examples, $P \mathrm{FE}_{2}$, the main prostaglandin, has been reported to inhibit apoptosis in colon cancer $^{10}$ and in radiation-treated epithelial cells ${ }^{11}$ through mechanisms involving the proteins of the $\mathrm{Bcl}-2$ family. On the other hands, $\mathrm{PGE}_{2}$ has been shown to induce apoptosis in human lymphocytes and in fibroblasts through multiple pathways. ${ }^{9,27}$ It is also well established that the increase in the synthesis of $\mathrm{PGE}_{2}$ during hypoxia/ischemic shock exacerbates stroke injury. ${ }^{28}$

Several enzymes have been shown to be involved in prostanoids synthesis downstream of the arachidonic acid. ${ }^{26}$ These enzymes have different cellular and tissue localizations and have different roles in various pathologies. ${ }^{29} \mathrm{mPGES}-1$ is a critical factor during post-ischemic neurological dysfunctions as its genetic knock out in mice significantly reduces the size of the infarct and the extent of caspase-dependent apoptosis. ${ }^{30} \mathrm{mPGES}-1$, the terminal enzyme in the synthesis of $\mathrm{PGE}_{2}{ }^{31}$ is encoded by a gene named pig12, which has been shown to be involved in early p53-induced apoptosis. ${ }^{32}$ We have shown that mPGES-1 overexpression in human high-grade glioma was correlated to a longer survival, ${ }^{8}$ even if mPGES-1 overexpression has often been observed in tumors compared with healthy tissues, notably in brain tumors. ${ }^{33}$ The same discrepancy can be observed in cell culture. mPGES-1 could namely promote the growth of a human glioma cell line ${ }^{34}$ through $\mathrm{PGE}_{2}$ extracellular pathway, whereas we showed that it was a proapoptotic enzyme in human brain tumor primary cultures through the activation of Bax by intracellular $\mathrm{PGE}_{2}$ and subsequent caspase activity. ${ }^{8}$ We confirmed that this discrepancy was linked to $\mathrm{PGE}_{2}$ localization, as the pharmacological sequestration of $\mathrm{PGE}_{2}$ was sufficient to induce apoptosis. $^{8}$

In this study, we show that this activating property of $\mathrm{PGE}_{2}$ toward $\mathrm{Bax}$ is closely linked to the $\mathrm{PGE}_{2}$ structure, as only the structurally related prostaglandin $A_{2}$ and 15-keto $P G E_{2}$, among all the challenged prostaglandins, retain this activating ability. We also report that the region in Bax encompassing $\mathrm{C} 126$ is the binding site of $\mathrm{PGE}_{2}$. However, as the Bax C126S point mutation does not abrogate the interaction between $\mathrm{Bax}$ and $P G E_{2}$ and as no covalent binding could be demonstrated between $P G E_{2}$ or $P G A_{2}$ and $C 126$, the entire interacting domain of $\mathrm{PGE}_{2}$ in Bax has still to be determined. Despite the fact that $\mathrm{Bax}^{\mathrm{C} 126 \mathrm{~S}}$ mutant is not a loss-of-function mutant, it is not able to respond to $\mathrm{PGE}_{2}$ as revealed by the conformationspecific immunoprecipitation with the $6 \mathrm{~A} 7$ anti-Bax antibody. Our interpretation of these observations is that $\mathrm{C} 126$ is not the only residue implicated in $\mathrm{PGE}_{2}$ binding to $\mathrm{Bax}$ but it is crucial to the subsequent activation of Bax induced by $P G E_{2}$. We show that $\mathrm{PGE}_{2}$ increases during the onset of apoptosis in various cell lines using different inducers, to a level consistent with the conditions used to activate Bax in cell-free assays (i.e., micromolar range). In contrast with the proapoptotic activity of $P G E_{2}$, we show that a closely related $\mathrm{PGH}_{2}$-derived prostaglandin, namely $P G D_{2}$, is a functional antagonist of $\mathrm{PGE}_{2}$ activity toward Bax. This might be surprising insofar as $P G D_{2}$ and its final metabolite 15 deoxy $\Delta^{12-14} P \mathrm{GJ}_{2}$ are implicated in the onset of apoptosis, through the activation of DP receptors or of PPAR $\gamma^{26}$ or of other targets. ${ }^{19}$ Payne et al. $^{35}$ also reported that L-PGDS loss was observed during transition from low grade to higher grade astrocytomas and was correlated to a poorer survival. However, our results demonstrate that $\mathrm{PGD}_{2}$ is not an absolute antiapoptotic compound, but rather a competitive inhibitor of $\mathrm{PGE}_{2}$ in $\mathrm{Bax}$ activation, as it does not preclude the Bid-induced activation of Bax. Besides, we only focused on the role played by $\mathrm{PGD}_{2}$ on Bax activation and we did not explore the overall targets of $\mathrm{PGD}_{2}$ and 15 deoxy $\Delta^{12-14} P \mathrm{GJ}_{2}$. The observation that L-PGDS inhibition induces Bax downregulation ${ }^{36}$ might be related to the important role played by $P \mathrm{PD}_{2} / \mathrm{PGE}_{2}$ ratio on cell survival. We have shown that silencing of L-PGDS increased the expression of PGES (Figure 4a), therefore the decrease of Bax could ensure cell survival of L-PGDSdeficient chondrocytes.

As described in Figure 6, we propose that apoptosis is under the control of the balance between intracellular concentrations of $\mathrm{PGE}_{2}$ and $\mathrm{PGD}_{2}$ and that of antiapoptotic extracellular $\mathrm{PGE}_{2}$. The liberation of this prostaglandin by dying cells would thus participate in the paracrine protection of adjacent cells or induce cell death depending on the nature of the tissue (Figure 6). This 'double-agent' mechanism could partly account for the equivocal and sometimes contradictory effects of COX-2 on apoptosis described in tumor cells. ${ }^{26}$ In addition, the release of $\mathrm{PGE}_{2}$ by dying cells could also influence tumor environment and have a role in the suppression of the immune system as suggested by Kokoglu et al. ${ }^{37}$

Small bioactive lipids, such as prostaglandins, thus appear as new potential candidates for the regulation of Bax activation. We show that $\mathrm{PGE}_{2}$ and Bid do not compete with each other but can rather cooperate in Bax activation and cell death induction. Bax activation could thus be considered as the integrative result of various changes in the intracellular environment occurring in the very early stages of apoptosis, including $\mathrm{BH} 3-$ only protein activation or release, antiapoptotic proteins oversupply, slight local physicochemical modifications and wavering in the $P G E_{2} / P D_{2}$ balance or in other lipid compounds. All of these environmental factors create a cellular context in which the most probable conformation of Bax according to thermodynamic considerations is either the inactive, globular conformation, or the active, outstretched conformation.

Our results definitely suggest that Bax activation should not only be regarded as a strict protein event but should be integrated in the overall cellular context, including bioactive lipids.

\section{Materials and Methods}

Materials. Antibodies were purchased from indicated companies: Bax 2D2 (amino acids 3-16, Sigma-Aldrich (Lyon, France), no. B8554), Bax 6A7 (amino acids 12-24, Abcam, Paris, France, no. ab5714), $F_{1}$-ATPase (Molecular Probes, Invitrogen, Cergy-Pontoise, France, no. A-21350), Cytochrome c (Chemicon, Millipore, Molsheim, France, no. MAB1501R). ${ }^{35}$ S-Met (Amersham Biosciences, GE 


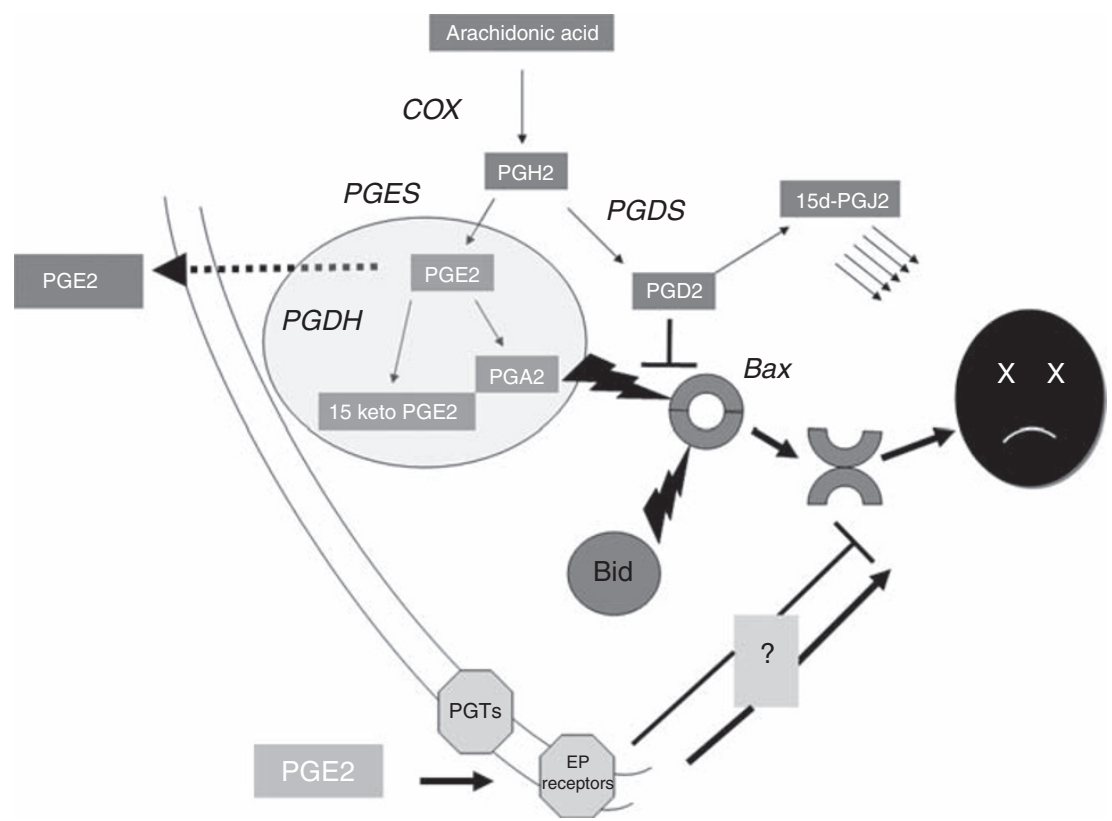

Figure 6 Bax activation is submitted to a double balance, namely the $\mathrm{PGE}_{2} / \mathrm{PGD}_{2}$ intracellular balance on the one hand and the intracellular/extracellular $P G E_{2}$ balance on the other hand. COX-2 product $P G H_{2}$ is further metabolized into $P G E_{2}$ and $P G D_{2}$. $P G E_{2}$ is rapidly exported to the extracellular compartment or transformed into $P G A_{2}$ and 15-keto $P G E_{2}$. $P G E_{2}, P A_{2}$ and 15-keto PGE2 all induce Bax activation, as Bid-like BH3-only proteins do. $\mathrm{PGD}_{2}$ inhibits this activation, despite its final metabolite 15 deoxy $\Delta^{12-14} \mathrm{PGJ} 2\left(15 \mathrm{~d}-\mathrm{PGJ}_{2}\right)$ is also reported to induce apoptosis. When exported in the extracellular compartment, $P G E_{2}$ can bind its membrane receptors $E P(1-4)$ and promote long-term survival of cancer cells

Healthcare, Orsay, France) labeled proteins were synthesized from cDNAs using the TNT-coupled transcription/translation system from Promega (Charbonnières-Les-Bains, France). Prostaglandins were purchased from Cayman Chemical (Interchim, France). Unless mentioned, chemical products and reagents were obtained from Sigma.

Immunoblots were quantified using the ImageJ software (NIH, Bethesda, MD, USA). Every experiment was repeated at least three independent times. Statistical sew were performed using the GraphPad software (San Diego, CA, USA; unpaired two-tailed $t$-test, unless mentioned otherwise). Unless mentioned, data shown represent mean values \pm S.E.M.

Cell free assay for Bax insertion. Mitochondria were prepared from normal rat liver and the cell-free association of Bax with the mitochondria was performed as described previously. ${ }^{16}{ }^{35} \mathrm{~S}$-Met-labeled Bax (2 fmol), $\mathrm{PGE}_{2}$ and isolated rat liver mitochondria ( $100 \mu \mathrm{g}$ mitochondrial proteins) were incubated in a standard import buffer for $1 \mathrm{~h}$ at $30^{\circ} \mathrm{C}$. Mitochondria were pelleted and samples were separated by SDS-PAGE. Gels were fixed and dried, and ${ }^{35} \mathrm{~S}$-labeled Bax was detected on a Phosphorlmager scanner. Image quantification was done using the ImageJ software.

Peptide scan. The experiments were performed as described in Bellot et al. ${ }^{13}$ Briefly, the peptide membranes were prepared on a MultiPep automated peptide synthesizer (Intavis AG, Köln, Germany). Bax sequence was divided into 12-mer peptides with a two amino acid frame shift. After the side chain deprotection of the peptides, the membrane was saturated by $5 \%$ BSA-PBS for $2 \mathrm{~h}$ at room temperature. Biotinylated prostaglandins ( $2 \mu \mathrm{M}$ in PBS) were incubated overnight at $4^{\circ} \mathrm{C}$. Extravidin-peroxidase was then incubated and the binding was assessed by ECL reaction. The binding intensities of prostaglandins for Bax-derived peptides were determined by quantification using the ImageJ software and converted to peptide-specific normalized units. Every experiment was repeated on four different membranes. The value attributed to each amino acid was the mean value of the spot intensities corresponding to the peptides covering this amino acid.

PGE $_{2}$-AChE Bax interaction. GBM cell lysates in excess ( $25 \mu \mathrm{g}$ protein/ condition) were incubated in a BSA-saturated 96-well plate, previously coated with the 2D2 anti-Bax antibody. After three washes with $0.1 \%$ Tween20-PBS, prostaglandins were incubated at the indicated concentration with acetylcholine-coupled $\mathrm{PGE}_{2}\left(\mathrm{PGE}_{2}-\mathrm{AChE}\right)$ added. The amount of $\mathrm{PGE}_{2}-\mathrm{AChE}$ bound to Bax was measured by the coloration of Ellman's reagent $(405 \mathrm{~nm})$. When indicated, cell lysates were treated by NAC or iodoacetamide for $1 \mathrm{~h}$ at $37^{\circ} \mathrm{C}$, then diluted $1: 24$ in $1 \%$ BSA-PBS before binding to the antibody-coated wells.

Microinjection experiments. Microinjection was performed as described by Lalier et $a l .^{8}$ Prostaglandins were co-injected with a dextran coupled to a fluorochrome (Oregon Green, Molecular Probes). The percentage of fluorescent cells exhibiting morphological apoptotic features was evaluated every hour following microinjection using an inverted fluorescent microscope (DMIRE2, Leica Microsystèmes SAS, Nanterre, France). Apoptosis was induced $1 \mathrm{~h}$ after injection, when indicated.

Cross-linking experiments. Bax-containing GBM cytosolic extracts were incubated with $5 \mu \mathrm{M}$ PGE2 or with Triton $\mathrm{X} 100$ as a positive control for $1 \mathrm{~h}$ at $30^{\circ} \mathrm{C}$. Cross-linking was then performed as described earlier ${ }^{16}$ and Bax was revealed by western blot.

Molecular modeling. Molecular modeling studies were performed using SYBYL software version 7.2. (Tripos Associates Inc, St. Louis, MO, USA) running on a Silicon Graphics Octane2 workstation. The geometry of $\mathrm{PGE}_{2}$ was subsequently optimized using the Tripos force field including the electrostatic term calculated from Gasteiger and Hückel atomic charges. Powell's method available in Maximin2 procedure was used for energy minimization until the gradient value was smaller than $0.001 \mathrm{kcal} / \mathrm{mol} . \AA$. The NMR structure of human proapoptotic protein Bax was obtained from the RCSB Protein Data Bank (code: 1F16; $\mathrm{http} / / \mathrm{www} . \mathrm{rcsb} .0 \mathrm{rg} / \mathrm{pdb} /)^{17}{ }^{17}$ The protein solvent accessible area with lipophilic potential was generated using the MOLCAD module in SYBYL 7.2. The program GOLD (version 3.1; CCDC, Cambridge, UK), an automated docking program (Jones et al. ${ }^{38}$ ), was used to dock $\mathrm{PGE}_{2}$ with its target protein. For the docking calculations, all residues of the protein were fixed, whereas $\mathrm{PGE}_{2}$ was flexible. An initial $\mathrm{H}$-bond constraint from the C-9 carbonyl group of $\mathrm{PGE}_{2}$ to the thiol (-SH) of $\mathrm{C} 126$ was applied. The most stable docking model was selected according to the best scored conformation predicted by the GoldScore ${ }^{38}$ and X-Score ${ }^{39}$ scoring functions. The complex was energy minimized using Powell's method available in Maximin2 procedure with the MMFF94 force field and a dielectric constant of 4.0 until the gradient value reached $0.1-\mathrm{kcal} / \mathrm{mol} . \AA . \AA$ 
Confocal analysis. For confocal analysis, the cells were fixed with $4 \%$ paraformaldehyde- $0.19 \%$ picric acid-PBS for $30 \mathrm{~min}$ at room temperature. After washing with PBS, the cells were permeabilized with $0.1 \%$ SDS-PBS for $10 \mathrm{~min}$ at room temperature, then saturated by $5 \%$ gelatin-PBS for $15 \mathrm{~min}$ at room temperature. The cells were incubated with indicated antibodies for $1 \mathrm{~h}$ at room temperature in $1 \%$ gelatin-PBS. The secondary antibodies used were coupled to a fluorochrome (Alexa 568 or 633 , Molecular Probes). Images were collected on a Leica TCS NT microscope with a $63 \times 1.3$ NA Fluotar objective (Leica, France).

Knock-down experiments. Enzyme knock down was assessed using two different shRNA sequences (Supplementary Figure S6) and its efficiencies checked by immunoblots and/or by measuring the synthesis of $\mathrm{PGE}_{2}$ or $\mathrm{PGD}_{2}$. Annealed double-strand oligonucleotides were cloned into a plasmid (pSilencer 2.1-U6 hygromycin vector, Ambion, Applied Biosystems, Courtaboeuf, France, no. AM5760) and transfected into GBM cells. Cells were further cultured with hygromycin $125 \mathrm{ng} / \mathrm{ml}$. Apoptosis was induced by staurosporine treatment $(150 \mathrm{nM}$ $12 \mathrm{~h}$ ). Cell death was assessed by Trypan blue exclusion; proteins were extracted and DEVDase activity was measured as described previously. ${ }^{16}$

For Bid and Bax knock-down experiment, commercial lentiviral particles were purchased from Sigma. Particles including a shRNA targeting GFP were used as a negative control. Infection was realized with a MOI of 10 and cells were further cultured with puromycin $1 \mu \mathrm{g} / \mathrm{ml}$. Four different shRNA were tested for each target protein and the most efficient was used for cell death experiments.

$\mathrm{PGE}_{2} / \mathrm{PGD}_{2}$ measurements. The amount of $\mathrm{PGE}_{2}$ was measured in cells lysates and culture medium using the $\mathrm{PGE}_{2}$ Biotrak EIA System (Amersham Biosciences) according to the manufacturer instructions. In all, $10^{4}$ cells were plated in 96-well plates the day before. Apoptotic treatment was adjusted to each cell line as follows: a range was realized to establish the amount of inducer triggering cell death in $24 \mathrm{~h}$, then cells were treated for $18 \mathrm{~h}$ to avoid cell disruption (assessed by Trypan blue exclusion) thereby enabling the measurement of intracellular $\mathrm{PGE}_{2}$. Treatments applied were $20 \mu \mathrm{M}$ etoposide for HCT116, HeLa, LN18 cells and $5 \mu \mathrm{M}$ etoposide for SH-SY5Y cells, $50 \mathrm{nM}$ staurosporine for all the four cell lines. Plates were read at $450 \mathrm{~nm}$. $\mathrm{PGE}_{2}$ concentrations were normalized to the protein concentration of the samples. Extracellular $\mathrm{PGD}_{2}$ was measured in serum-free medium using the Prostaglandin $D_{2}$ EIA kit (Cayman Chemical Company, no. 512021) according to the manufacturer.

\section{Conflict of interest}

The authors declare no conflict of interest.

Acknowledgements. This work was supported by a special grant from the Ligue contre le Cancer (Equipe labellisée Ligue). We thank Dr. J Grassi (CEA/Saclay, France) for the gift of AChE-coupled $\mathrm{PGE}_{2}$ and recombinant $\mathrm{AChE}$ and Gaëlle Blanchet (Service de Biochimie, Faculté de Medecine de Nantes, France) for technical assistance.

\section{Author contributions}

Lisenn Lalier performed the in vitro experiments and drafted the manuscript. Pierre Francois Cartron performed the acellular studies, Christophe Olivier performed some of the microinjection experiments, Gwenola Bougras carried out the phenotyping characterization of the cell lines and Lisa Oliver the immunohistochemical characterization and confocal studies. Cedric Logé and Jean-Michel Robert participated in the molecular modeling of $\mathrm{PGE}_{2} / \mathrm{Bax}$ interaction. Francois $\mathrm{M}$ Vallette conceived of the study and wrote the final version of the manuscript.

1. Chipuk JE, Bouchier-Hayes L, Green DR. Mitochondrial outer membrane permeabilization during apoptosis: the innocent bystander scenario. Cell Death Differ 2006; 13: 1396-1402.

2. Green DR. At the gates of death. Cancer Cell 2006; 9: 328-330.

3. Youle RJ, Strasser A. The BCL-2 protein family: opposing activities that mediate cell death. Nat Rev Mol Cell Biol 2008; 9: 47-59.

4. Giam M, Huang DC, Bouillet P. BH3-only proteins and their roles in programmed cell death. Oncogene 2008; 27(Suppl 1): S128-S136.

5. Cartron PF, Oliver L, Mayat E, Meflah K, Vallette FM. Impact of $\mathrm{pH}$ on Bax alpha conformation, oligomerisation and mitochondrial integration. FEBS Lett 2004; 578: 41-46.
6. Khaled AR, Kim K, Hofmeister R, Muegge K, Durum SK. Withdrawal of IL-7 induces Bax translocation from cytosol to mitochondria through a rise in intracellular $\mathrm{pH}$. Proc Natl Acad Sci USA 1999; 96: 14476-14481.

7. Pagliari LJ, Kuwana T, Bonzon C, Newmeyer DD, Tu S, Beere HM et al. The multidomain proapoptotic molecules Bax and Bak are directly activated by heat. Proc Natl Acad Sci USA 2005; 102: 17975-17980.

8. Lalier L, Cartron PF, Pedelaborde F, Olivier C, Loussouarn D, Martin SA et al. Increase in PGE2 biosynthesis induces a Bax dependent apoptosis correlated to patients' survival in glioblastoma multiforme. Oncogene 2007; 26: 4999-5009.

9. Huang SK, White ES, Wettlaufer SH, Grifka H, Hogaboam CM, Thannickal VJ et al. Prostaglandin $\mathrm{E}(2)$ induces fibroblast apoptosis by modulating multiple survival pathways. Faseb J 2009; 23: 4317-4326.

10. Sheng H, Shao J, Morrow JD, Beauchamp RD, DuBois RN. Modulation of apoptosis and Bcl-2 expression by prostaglandin E2 in human colon cancer cells. Cancer Res 1998; 58: 362-366.

11. Tessner TG, Muhale F, Riehl TE, Anant S, Stenson WF. Prostaglandin E2 reduces radiation-induced epithelial apoptosis through a mechanism involving AKT activation and bax translocation. J Clin Invest 2004; 114: 1676-1685.

12. Tai $\mathrm{HH}$, Ensor $\mathrm{CM}$, Tong M, Zhou H, Yan F. Prostaglandin catabolizing enzymes. Prostaglandins Other Lipid Mediat 2002; 68-69: 483-493.

13. Bellot G, Cartron PF, Er E, Oliver L, Juin P, Armstrong LC et al. TOM22, a core component of the mitochondria outer membrane protein translocation pore, is a mitochondrial receptor for the proapoptotic protein Bax. Cell Death Differ 2007; 14: 785-794.

14. Annis MG, Soucie EL, Dlugosz PJ, Cruz-Aguado JA, Penn LZ, Leber B et al. Bax forms multispanning monomers that oligomerize to permeabilize membranes during apoptosis. Embo J 2005; 24: 2096-2103.

15. Cartron PF, Gallenne T, Bougras G, Gautier F, Manero F, Vusio P et al. The first alpha helix of Bax plays a necessary role in its ligand-induced activation by the $\mathrm{BH}$-only proteins Bid and PUMA. Mol Cell 2004; 16: 807-818.

16. Cartron PF, Juin P, Oliver L, Martin S, Meflah K, Vallette FM. Nonredundant role of Bax and Bak in Bid-mediated apoptosis. Mol Cell Biol 2003; 23: 4701-4712.

17. Suzuki M, Youle RJ, Tjandra N. Structure of Bax: coregulation of dimer formation and intracellular localization. Cell 2000; 103: 645-654.

18. Gharbi S, Garzon B, Gayarre J, Timms J, Perez-Sala D. Study of protein targets for covalent modification by the antitumoral and anti-inflammatory prostaglandin PGA1: focus on vimentin. J Mass Spectrom 2007; 42: 1474-1484.

19. Perez-Sala D, Cernuda-Morollon E, Canada FJ. Molecular basis for the direct inhibition of AP-1 DNA binding by 15-deoxy-Delta 12,14-prostaglandin J2. J Biol Chem 2003; 278: 51251-51260.

20. Gavathiotis E, Suzuki M, Davis ML, Pitter K, Bird GH, Katz SG et al. BAX activation is initiated at a novel interaction site. Nature 2008; 455: 1076-1081.

21. Kapoor M, Kojima F, Yang L, Crofford LJ. Sequential induction of pro- and antiinflammatory prostaglandins and peroxisome proliferators-activated receptor-gamma during normal wound healing: a time course study. Prostaglandins Leukot Essent Fatty Acids 2007; 76: 103-112

22. Qu WM, Huang ZL, Xu XH, Aritake K, Eguchi N, Nambu F et al. Lipocalin-type prostaglandin D synthase produces prostaglandin D2 involved in regulation of physiologica sleep. Proc Natl Acad Sci USA 2006; 103: 17949-17954.

23. Telleria-Diaz A, Ebersberger A, Vasquez E, Schache F, Kahlenbach J, Schaible HG. Different effects of spinally applied prostaglandin D2 on responses of dorsal horn neurons with knee input in normal rats and in rats with acute knee inflammation. Neuroscience 2008; 156: 184-192

24. Wang K, Yin XM, Chao DT, Milliman CL, Korsmeyer SJ. BID: a novel BH3 domain-only death agonist. Genes Dev 1996; 10: 2859-2869.

25. Moreau C, Cartron PF, Hunt A, Meflah K, Green DR, Evan G et al. Minimal BH3 peptides promote cell death by antagonizing anti-apoptotic proteins. J Biol Chem 2003; 278: 19426-19435.

26. Wang D, Dubois RN. Eicosanoids and cancer. Nat Rev Cancer 2010; 10: 181-193.

27. Pica F, Franzese O, D'Onofrio C, Bonmassar E, Favalli C, Garaci E. Prostaglandin E2 induces apoptosis in resting immature and mature human lymphocytes: a c-Mycdependent and Bcl-2-independent associated pathway. J Pharmacol Exp Ther 1996; 277 1793-1800.

28. Chen C, Bazan NG. Lipid signaling: sleep, synaptic plasticity, and neuroprotection Prostaglandins Other Lipid Mediat 2005; 77: 65-76.

29. Smyth EM, Grosser T, Wang M, Yu Y, FitzGerald GA. Prostanoids in health and disease. $J$ Lipid Res 2009; 50(Suppl): S423-S428.

30. Ikeda-Matsuo Y, Ota A, Fukada T, Uematsu S, Akira S, Sasaki Y. Microsomal prostaglandin E synthase-1 is a critical factor of stroke-reperfusion injury. Proc Natl Acad Sci USA 2006; 103: 11790-11795.

31. Samuelsson B, Morgenstern R, Jakobsson PJ. Membrane prostaglandin E synthase-1: a novel therapeutic target. Pharmacol Rev 2007; 59: 207-224.

32. Polyak K, Xia Y, Zweier JL, Kinzler KW, Vogelstein B. A model for p53-induced apoptosis. Nature 1997; 389: 300-305.

33. Mattila S, Tuominen H, Koivukangas J, Stenback F. The terminal prostaglandin synthases mPGES-1, mPGES-2, and CPGES are all overexpressed in human gliomas. Neuropathology 2009; 29: 156-165. 
34. Payner T, Leaver HA, Knapp B, Whittle IR, Trifan OC, Miller S et al. Microsomal prostaglandin $\mathrm{E}$ synthase-1 regulates human glioma cell growth via prostaglandin $\mathrm{E}(2)$-dependent activation of type II protein kinase A. Mol Cancer Ther 2006; 5: 1817-1826.

35. Payne CA, Maleki S, Messina M, O'Sullivan MG, Stone G, Hall NR et al. Loss of prostaglandin D2 synthase: a key molecular event in the transition of a low-grade astrocytoma to an anaplastic astrocytoma. Mol Cancer Ther 2008; 7: 3420-3428.

36. Zhu F, Wang P, Kontrogianni-Konstantopoulos A, Konstantopoulos K. Prostaglandin $(\mathrm{PG}) \mathrm{D}(2)$ and 15-deoxy-Delta(12,14)-PGJ(2), but not PGE(2), mediate shear-induced chondrocyte apoptosis via protein kinase A-dependent regulation of polo-like kinases. Cell Death Differ 17: 1325-1334.

37. Kokoglu E, Tuter Y, Sandikci KS, Yazici Z, Ulakoglu EZ, Sonmez H et al. Prostaglandin E2 levels in human brain tumor tissues and arachidonic acid levels in the plasma membrane of human brain tumors. Cancer Lett 1998; 132: 17-21.

38. Jones $G$, Willett $P$, Glen RC, Leach AR, Taylor R. Development and validation of a genetic algorithm for flexible docking. J Mol Biol 1997; 267: 727-748.

39. Wang R, Lai L, Wang S. Further development and validation of empirical scoring functions for structure-based binding affinity prediction. J Comput Aided Mol Des 2002; 16: 11-26.

Supplementary Information accompanies the paper on Cell Death and Differentiation website (http://www.nature.com/cdd) 